\title{
A variation of functional equations related to sine type functions
}

\author{
Bin $\mathrm{He}^{1}$ and Guangsheng Wei ${ }^{1}$ \\ ${ }^{1}$ Shaanxi Normal University
}

December 15, 2021

\begin{abstract}
In this paper, we consider a class of functional equation $\mathrm{Q}(\lambda) \mathrm{Y}(\lambda)-\mathrm{P}(\lambda) \mathrm{Z}(\lambda)=\eta$ related to sine type functions, where the known $\mathrm{P}, \mathrm{Q}$ are appropriate entire functions of exponential type. We are concerned with the existence and uniqueness of the solution $(\mathrm{Y}, \mathrm{Z})$ under certain circumstances. Furthermore, we modify the Lagrange interpolation to deal with the situation of the interpolation nodes being counted by multiplicities, which is significant to solve the above functional equation.
\end{abstract}

\section{Hosted file}

manuscript.pdf available at https://authorea.com/users/451273/articles/549485-a-variationof-functional-equations-related-to-sine-type-functions 